\title{
Direct-to-Consumer Promotion of Prescription Drugs on Mobile Devices: Content Analysis
}

Kathryn J Aikin ${ }^{1}$, PhD; Helen W Sullivan ${ }^{1}$, MPH, PhD; Suzanne Dolina², MPH; Molly Lynch², MPH; Linda B Squiers $^{2}, \mathrm{PhD}$

${ }^{1}$ Office of Prescription Drug Promotion, Center for Drug Evaluation, US Food and Drug Administration, Silver Spring, MD, United States

${ }^{2}$ RTI International, Research Triangle Park, NC, United States

Corresponding Author:

Kathryn J Aikin, PhD

Office of Prescription Drug Promotion

Center for Drug Evaluation

US Food and Drug Administration

10903 New Hampshire Avenue

Silver Spring, MD, 20993

United States

Phone: 13017961200

Fax: 13018478444

Email: kathryn.aikin@fda.hhs.gov

\section{Abstract}

Background: US Food and Drug Administration (FDA) regulations state that any prescription drug promotion that presents drug benefits to consumers must also disclose certain information about the drug's risks in a similar manner. Nearly three-quarters of all US mobile phone subscribers use a smartphone, and over half report receiving mobile advertisements on their device.

Objective: The objective of this project was to investigate how prescription drugs are being promoted to consumers using mobile technologies. We were particularly interested in the presentation of drug benefits and risks, with regard to presence, placement, and prominence.

Methods: We analyzed a sample of 51 mobile promotional communications and their associated linked landing pages. We assessed the content and format of the mobile communications and landing pages with regard to presentation of drug benefits and risks.

Results: Of the 51 mobile communications we coded, $41 \%$ (21/51) were product claim communications (includes the drug name, benefits, and risks), 22\% (11/51) were reminder communications (includes drug name only), and 37\% (19/51) were help-seeking communications (includes information about the medical condition but not the drug name). Some of the product claim communications $(5 / 21,24 \%)$ required scrolling to see all the benefit information; in contrast, $95 \%(20 / 21)$ required scrolling to see all the risk information. Of the 19 product claim communications that presented both benefits and risks, 95\% (18/19) presented benefits before risks and 47\% (9/19) used a bigger font for benefits than for risks. Most mobile communications (35/51, $69 \%$ ) linked to branded drug websites with both benefits and risks, $25 \%$ (13/51) linked to a landing page with benefits but no visible risks, and $6 \%$ (3/51) linked to a landing page with risks but no visible benefits. Few landing pages (4/51, 8\%) required scrolling to see all the benefit information; in contrast, $51 \%(26 / 51)$ required scrolling to see all the risk information. Of the 35 landing pages with both benefit and risk information, 71\% (25/35) presented benefits before risks and 51\% (18/35) used a bigger font for benefits than for risks.

Conclusions: These results indicate that, while risks and benefits are both represented in mobile communications and their associated landing pages, they are not equally prominent and accessible. This has implications for compliance with FDA fair balance regulations.

(J Med Internet Res 2017;19(7):e225) doi: 10.2196/jmir.7306

\section{KEYWORDS}

direct-to-consumer promotion; direct-to-consumer advertising; mobile devices; prescription drugs 


\section{Introduction}

Information, entertainment, and advertisement consumption has been steadily moving away from print and network television stations to more specialized and targeted digital outlets, including Internet and mobile devices. By 2012, half of all mobile subscribers in the United States owned a smartphone [1], jumping to nearly three-quarters within 3 years [2]. In 2013, 57\% of US smartphone owners reported receiving mobile ads at least once a day [3]. Prescription drug direct-to-consumer (DTC) promotion expenditure on the Internet experienced triple-digit growth between 2005 and 2009, compared with a decrease in other media channels [4]. One report [5] estimated that 3 billion to 7 billion pharmaceutical and drug promotional messages were being delivered online each month. Another noted that US health care and pharmaceutical advertisers spent US \$373 million on mobile formats in 2014 [6]. Nevertheless, prescription drug promotion, while well represented on the Internet in the form of websites, has been slower to branch into mobile promotion beyond paid searches. One possible cause of this could be the issuance of US Food and Drug Administration (FDA) "enforcement" warning and untitled letters about sponsored links on Internet search engines in 2009 [7], which stated that online promotion is subject to existing laws and implementing regulations $[8,9]$. In particular, the US Food, Drug, and Cosmetic Act and implementing regulations state that any prescription drug promotion that presents drug benefits to consumers must also disclose certain information about the drug's risks in a similar manner. This concept of "fair balance" may be challenging in mobile promotional communications (hereafter referred to as "mobile communications"), where there are often limitations on the amount of information that can be presented.

Content analyses have found fair balance lacking in DTC marketing in print [10-12], television [11,13-15], websites [16-18], social media sites [19], and Internet banners [20]. It is also important to have an accurate picture of the mobile promotion landscape in order to make informed decisions about mobile DTC promotion. The purpose of this content analysis was to explore the presentation of drug benefits and risks in (1) mobile communications and (2) landing pages (ie, the first page of the website to which the communication linked).

\section{Methods}

After evaluating the capabilities of several companies, we chose to use a commercially available dataset of mobile-enhanced DTC promotional communications from Competitrack (Market Track, LLC, Chicago, IL, USA). Competitrack monitors 100 leading apps and mobile-optimized websites, including mobile devices-specifically, iPhones, Android phones, iPads, and Android tablets-by sampling hundreds of top-rated apps and websites to identify those that carry the most distinctive and requested consumer advertising. This media universe is reviewed on a regular basis to identify emerging apps and websites with relevant advertising. Competitrack's database includes information about the type of device used to find the ad, jpg files of the ads, ad landing pages, URLs (if available), and general information (eg, site or app where the ad was found, and type [news, weather, shopping, health], date, and brand). We used Competitrack's database to download general information about prescription drug communications, static images of the full communication, and images of the landing pages (jpg files). Although a few of the mobile communications were interactive, we chose to use a "snapshot in time" approach to capture and code communications and landing pages at 1 point in time to avoid problems of replicability. This method allowed 2 coders to analyze identical ads and landing pages to calculate interrater reliability. We identified 266 mobile communications from May 2012 to May 2014.

We selected eligible mobile communications using the following criteria: (1) the communication and the landing page had to be viewable, (2) only 1 communication per brand could be included, (3) the promoted branded prescription drug had to be regulated by FDA's Center for Drug Evaluation and Research (CDER) [21], and (4) the communication had to be directed at consumers. We excluded 178 duplicates, plus 22 that were not prescription products regulated by CDER, and 9 due to landing page or mobile screenshot viewing issues. We excluded an additional 6 communications during coding: 4 targeted health care providers rather than consumers, 1 had no mobile communication included, and 1 had no landing page. This resulted in a sample of 51 mobile communications (Table 1). 
Table 1. Sample characteristics of mobile communications promoting prescription drugs $(\mathrm{N}=51)$.

\begin{tabular}{|c|c|c|c|c|}
\hline Drug name & Source & Source type & Device & Year \\
\hline Abilify & CBS News & App & iPhone & 2013 \\
\hline Androgel & $\mathrm{CNN}$ & Website & iPad & 2013 \\
\hline Axiron & Fox News & Website & iPad & 2012 \\
\hline Botox & WeatherBug & App & iPhone & 2013 \\
\hline Bydureon & AroundMe & App & Android Phone & 2014 \\
\hline Celebrex & Fox News & App & iPhone & 2013 \\
\hline Chantix & About.com & Website & iPad & 2013 \\
\hline Cialis & WeatherBug & Website & Android Phone & 2012 \\
\hline Complera & $\mathrm{CNBC}$ & Website & Android Phone & 2013 \\
\hline Copaxone & eHow & Website & iPhone & 2014 \\
\hline Cymbalta & $\mathrm{CNN}$ & Website & Android Phone & 2013 \\
\hline Dexilant & Dictionary.com & App & Android Phone & 2013 \\
\hline Diclegis & TheStreet & App & Android Phone & 2013 \\
\hline Dulera & Weatherbug & Website & Android Phone & 2012 \\
\hline Eliquis & Fox News & Website & iPad & 2013 \\
\hline EpiPen & eHow & Website & iPhone & 2013 \\
\hline Evista & Weather.com & Website & iPad & 2013 \\
\hline Finacea & About.com & Website & iPad & 2014 \\
\hline Gilenya & MSNBC & Website & iPad & 2013 \\
\hline Horizant & About.com & Website & iPad & 2013 \\
\hline Incivek & About.com & Website & Android Phone & 2012 \\
\hline Intermezzo & New York Times & Website & iPad & 2013 \\
\hline Intuniv & Learn Spanish Vocabulary Lite & App & Android Phone & 2013 \\
\hline Isentress & About.com & Website & iPad & 2013 \\
\hline Januvia & WeatherBug & Website & iPad & 2013 \\
\hline Latuda & CareerBuilder.com & Website & iPad & 2014 \\
\hline Lovaza & Fox News & Website & iPhone & 2013 \\
\hline Lunesta & WeatherBug & App & Android Tablet & 2013 \\
\hline Mirena & Fox Sports & Website & iPad & 2013 \\
\hline Myrbetriq & eHow & Website & Android Phone & 2013 \\
\hline Nasonex & AccuWeather & App & iPad & 2012 \\
\hline Nexplanon & Craigslist Mobile & App & Android Phone & 2013 \\
\hline NuvaRing & WeatherBug & App & iPhone & 2012 \\
\hline Nuvigil & Fox Sports & Website & iPad & 2013 \\
\hline ParaGard IUD & Dailymotion & Website & Android Phone & 2012 \\
\hline PlanB & TweetCaster & App & Android Phone & 2012 \\
\hline Staxyn & Fox News & Website & iPad & 2013 \\
\hline Stelara & The Weather Channel & App & iPhone & 2013 \\
\hline Strattera & Expedia & Website & iPhone & 2013 \\
\hline Stribild & About.com & Website & iPad & 2013 \\
\hline Suboxone & Fox News & App & iPhone & 2013 \\
\hline Symbicort & Weather.com & Website & iPhone & 2013 \\
\hline
\end{tabular}




\begin{tabular}{lllll}
\hline Drug name & Source & Source type & Device & Year \\
\hline Synthroid & About.com & Website & iPad & iPhone \\
Tamiflu & CBS Local YourDay & App & iPhone & 2013 \\
Velcade & New York Times & Website & iPhone & 2013 \\
Vesicare & eHow & Website & iPad & 2013 \\
Viagra & NFL.com & Website & Android Phone & 2013 \\
Vyvanse & Craigslist Mobile & App & iPad & 2013 \\
Xarelto & AOL & Website & iPad & 2013 \\
Xeljanz & CNN & Website & iPad & 2013 \\
Zetonna & AccuWeather & App & \\
\hline
\end{tabular}

Two raters independently double coded $10 \%$ of the sample (5 mobile communications and their related landing pages) to refine the coding scheme, and double coded an additional $10 \%$ of the sample to determine interrater reliability ( $\kappa=.92$ for mobile communication codes and $\kappa=.83$ for landing page codes). Disagreements were resolved through discussion. We coded the type of mobile communications and landing pages, the prominence and placement of benefit and risk information, and the presence of links. The type and amount of risk and benefit information in each communication was determined by examining the FDA-approved product labeling for that product. We coded the part(s) of the landing page that were viewable on the screenshot (see Multimedia Appendix 1 for examples). In cases where partial information was visible and ended mid sentence or a capture included additional information that could be accessed through scrolling, as indicated by the presence of a scroll bar, we made the reasonable assumption that it continued below the available screenshot.

\section{Results}

\section{Mobile Communication Content and Format}

Of the 51 mobile communications we coded, $41 \%$ (21/51) were product claim communications, $22 \%$ (11/51) were reminder communications, and 37\% (19/51) were help-seeking communications (see Multimedia Appendix 2 for examples).
Scrolling was needed to see all the benefit information on $24 \%$ $(5 / 21)$ of the product claim mobile communications. In contrast, scrolling was needed to see all the risk information on all but 1 of the product claim mobile communications (20/21, 95\%). Of the 21 communications, $2(10 \%)$ had additional benefit information available with a link or tab, and $1(1 / 21,5 \%)$ had additional risk information available with a link or tab. Of the 19 product claim communications that presented both benefits and risks, 95\% (18/19) presented benefits before risks, $47 \%$ $(9 / 19)$ used a bigger font for benefits than for risks, $16 \%(3 / 19)$ used a bigger font size for risks, and 37\% (7/19) used the same size font for both.

Of the 51 mobile communications, 37 (72\%) included links or tabs to access additional information. The most common link or tab we coded was to the FDA-approved prescribing information [22] (Tables 2 and 3).

\section{Landing Page Content and Format}

The majority of the mobile communications $(35 / 51,69 \%)$ linked to product claim websites, $25 \%$ (13/51) linked to landing pages with the drug name and benefit information without visible risk information, and $6 \%(3 / 51)$ linked to landing pages with the drug name and risk information without visible benefit information. Some help-seeking and reminder communications linked to landing pages with the drug name and benefit information without visible risk information (Table 4).

Table 2. Types of links and tabs $(\mathrm{N}=51)$.

\begin{tabular}{|c|c|c|c|}
\hline Type of link or tab & Definition & $\begin{array}{l}\text { Mobile promotional } \\
\text { communication, } \\
\%(\mathrm{n})\end{array}$ & $\begin{array}{l}\text { Landing page, } \\
\%(\mathrm{n})\end{array}$ \\
\hline Prescribing information & $\begin{array}{l}\text { A compilation of information about the product, written for the health care practi- } \\
\text { tioner audience, approved by the FDA }{ }^{\text {a }} \text {, based on the agency's thorough analysis } \\
\text { of the new drug application or biologics license application submitted by the appli- } \\
\text { cant. This labeling contains information necessary for safe and effective use. }\end{array}$ & $37(19)$ & $82(42)$ \\
\hline MedGuide & $\begin{array}{l}\text { FDA-approved information that comes with some prescription medicines, determined } \\
\text { to pose a serious and significant public health concern. The MedGuide is designed } \\
\text { to help patients avoid serious adverse events. MedGuides are a specific category } \\
\text { of Patient Labeling. }\end{array}$ & $22(11)$ & $53(27)$ \\
\hline FDA website & www.fda.gov or www.fda.gov/medwatch & $14(7)$ & $16(8)$ \\
\hline Patient information & Labeled as information for patients, patient information, or patient package insert. & $6(3)$ & $29(15)$ \\
\hline
\end{tabular}

${ }^{a}$ FDA: US Food and Drug Administration. 
Table 3. Types of links and tabs by type of mobile promotional communication.

\begin{tabular}{|c|c|c|c|}
\hline \multirow[t]{2}{*}{ Type of link or tab } & \multicolumn{3}{|c|}{ Type of communication, \% (n) } \\
\hline & $\begin{array}{l}\text { Product claim } \\
(\mathrm{n}=21)\end{array}$ & $\begin{array}{l}\text { Reminder } \\
(\mathrm{n}=11)\end{array}$ & $\begin{array}{l}\text { Help seeking } \\
(\mathrm{n}=19)\end{array}$ \\
\hline Prescribing information & $81(17)$ & $18(2)$ & $0(0)$ \\
\hline MedGuide & $52(11)$ & $0(0)$ & $0(0)$ \\
\hline FDA website & $33(7)$ & $0(0)$ & $0(0)$ \\
\hline Patient information & $14(3)$ & $0(0)$ & $0(0)$ \\
\hline
\end{tabular}

Table 4. Type of mobile promotional communication by type of landing page $(\mathrm{N}=51)$.

\begin{tabular}{|c|c|c|c|c|}
\hline \multirow[t]{2}{*}{ Type of communication } & \multicolumn{3}{|l|}{ Type of landing page, $\%(\mathrm{n})$} & \multirow[t]{2}{*}{ Total } \\
\hline & Product claim (name, benefits, and risks) & Drug name and benefits & Drug name and risks & \\
\hline Product claim & $29(15)$ & $12(6)$ & $0(0)$ & $41(21)$ \\
\hline Reminder & $14(7)$ & $6(3)$ & $2(1)$ & $22(11)$ \\
\hline Help seeking & $25(13)$ & $8(4)$ & $4(2)$ & $37(19)$ \\
\hline Total & $69(35)$ & $25(13)$ & $6(3)$ & $100(51)$ \\
\hline
\end{tabular}

Nearly all $(48 / 51,94 \%)$ of the landing pages had visible benefit information, and $88 \%(45 / 51)$ had additional benefit information available with a link or tab. Approximately three-quarters of landing pages had visible risk information $(38 / 51,74 \%)$ and $86 \%(44 / 51)$ had additional risk information available with a link or tab. Scrolling was needed to see all the benefit information on $8 \%(4 / 51)$ of the landing pages. In contrast, scrolling was needed to see all the risk information on $51 \%$ $(26 / 51)$ of the landing pages.

Of the 35 landing pages with both benefit and risk information, $71 \%(25 / 35)$ presented benefits before risks, $51 \%$ (18/35) used a bigger font for benefits than for risks, $3 \%$ (1/35) used a bigger font size for risks, and $46 \%(16 / 35)$ used the same size font for both.

Nearly all the landing pages $(48 / 51,94 \%)$ included links or tabs to access additional information. The most common link or tab we coded was to the FDA-approved prescribing information (Table 2).

\section{Discussion}

DTC marketing can affect important public health outcomes [23-25], and mobile DTC promotion continues to increase exponentially [26]. Therefore, it is important to understand the content of this promotion. Surprisingly, 22\% of mobile communications were reminder communications, a higher proportion than expected given the scarcity of reminders overall. An informal survey of DTC television ads reveals almost no reminder ads in that medium, which may be a direct result of the Pharmaceutical Research and Manufacturers of America DTC guidelines that encourage DTC ads that name a product to also include both risk and indication information [27]. Reminder communications may be suited to the mobile space because they do not have to accommodate benefit and risk information. Enforcement in other space-limited Internet venues likely also affected the types of mobile communications used [28]. Despite FDA guidance in this area [9], sponsors who remain unsure about how to implement a fairly balanced product claim promotion in this medium may opt instead to use a reminder communication to link to the drug's promotional website [29].

When mobile communications included both benefits and risks, benefits appeared to be more prominent and easily accessible than risks, although we did not test for significant differences. This echoes prior research across a broad range of marketing platforms and raises concerns about whether fair balance requirements are being met in the mobile marketing of prescription drugs in the United States. Similarly, and consistent with past research, benefits also appeared to be more prominent than risks on landing pages $[18,20]$. It may be that the apparent difference in scrolling needed is because there is often more information in the risk section of approved labeling than in the indication section. Regardless, if risk information is available only through scrolling or a link, consumers may be less likely to access it and may miss important information [30]. Sponsors should ensure that benefit and risk information in mobile communications and on landing pages is equally prominent and accessible to address fair balance.

Some help-seeking and reminder communications linked to a website with the drug name and benefit information but without visible risk information. The FDA has expressed concerns about linking a drug to an indication without accompanying risk information [31]. Moreover, research has shown that consumers confuse disease information with branded prescription drug information when the two are presented together [32] or associated by link [33]. Situations where reminder or help-seeking communications are linked to full product claim websites may require extra care to ensure the information is truthful, balanced, and nonmisleading.

\section{Limitations}

First, the dataset we used consisted mostly of static screenshots. Thus, we could not code interactive features or information that could be viewed only by scrolling. If the screenshot consisted 
only of the "above the fold" section of a landing page, we could not determine whether risks or benefits were presented "below the fold." Second, content analysis allows for in-depth analysis of information, but it cannot provide information on how often consumers view mobile communications, what information they understand, or how often they view the landing page. Third, Competitrack did not have an established protocol regarding the orientation of the device. This was done at the discretion of the capture person, but some apps presented the page in landscape by default. As a result, there could potentially be differences in what was captured in a screenshot depending on the device.

\section{Conclusions}

Consumers are increasingly going online for health information, and as digital marketing for prescription drugs is increasing, consumers are more likely to encounter these mobile communications. At the same time, lack of fair balance generally, and minimization of risk information in particular, continue to be frequently cited in FDA letters [34]. Our findings suggest that sponsors continue to struggle with these issues across promotional platforms. Recent FDA guidance on character space-limited platforms [8,9] may help sponsors navigate these issues. The results of this analysis, particularly with respect to the persistent lack of fair balance, may provide useful information to regulators as they consider the available data applicable to policy. Additionally, continued surveillance of DTC marketing online and in mobile communications is needed to ensure that consumers have access to fairly balanced, accurate, and nonmisleading information about medical products.

\section{Acknowledgments}

The study was supported by the Office of Prescription Drug Promotion, US Food and Drug Administration. We would like to thank Lisa Gilbert for her contributions to designing the study.

\section{Authors' Contributions}

KA and HS contributed to study design, methodology, data analysis, and manuscript preparation. LS, ML, and DS contributed to methodology and data analysis.

\section{Conflicts of Interest}

None declared.

\section{Multimedia Appendix 1}

Landing page examples.

[PDF File (Adobe PDF File), 463KB-Multimedia Appendix 1]

\section{Multimedia Appendix 2}

Type of mobile promotional communication in sample.

[PDF File (Adobe PDF File), 187KB-Multimedia Appendix 2]

\section{References}

1. Nielsen. Smartphones account for half of all mobile phones, dominate new phone purchases in the US. 2012 Mar 29. URL: http://www.nielsen.com/us/en/insights/news/2012/ smartphones-account-for-half-of-all-mobile-phones-dominate-new-phone-purchases-in-the-us.html [accessed 2017-06-16] [WebCite Cache ID 6ow7858ne]

2. Poushter J. Smartphone ownership and internet usage continues to climb in emerging economies. Washington, DC: Pew Research Center; 2017 Mar 13. URL: http://www.pewglobal.org/files/2016/02/ pew research center global technology report final february 22 2016.pdf [accessed 2017-06-14] [WebCite Cache ID $\underline{\text { 6rDTqDlkA] }}$

3. Nielsen. Ads on the move: how messaging has gone mobile. 2013 Feb 26. URL: http://www.nielsen.com/us/en/insights/ news/2013/ads-on-the-move-how-messaging-has-gone-mobile.html [accessed 2017-03-13] [WebCite Cache ID 6ow7HJP60]

4. Mackey TK, Cuomo RE, Liang BA. The rise of digital direct-to-consumer advertising? Comparison of direct-to-consumer advertising expenditure trends from publicly available data sources and global policy implications. BMC Health Serv Res 2015 Jun 19;15:236 [FREE Full text] [doi: 10.1186/s12913-015-0885-1] [Medline: 26084705]

5. comScore. New pharma digital marketing benchmarks show that online pharmaceutical marketing continues to drive brand awareness, favorability and conversions. 2014 Jul 10. URL: http://www.comscore.com/Insights/Press-Releases/2014/7/ New-Pharma-Digital-Marketing-Benchmarks-Show-that-Online-Pharmaceutical-Marketing-Continues-to-Dive-Brand-Awareness-Favorability-and-Conversions [accessed 2017-03-13] [WebCite Cache ID 6ow7P6wZW] 
6. eMarketer. For US healthcare and pharma ad spending, balance tips toward direct response. 2014 May 27. URL: https:/ /www.emarketer.com/Article/US-Healthcare-Pharma-Ad-Spending-Balance-Tips-Toward-Direct-Response/1010873 [accessed 2017-03-13] [WebCite Cache ID 6ow7YUetQ]

7. Favole J. Wall Street Journal. 2009 Apr 4. FDA warns drug firms over internet ads URL: http://www.wsj.com/articles/ SB123879766861188121 [accessed 2016-11-15] [WebCite Cache ID 6m2tRsIVp]

8. Abrams T. FDA issues draft guidances for industry on social media and internet communications about medical products: designed with patients in mind. Silver Spring, MD: U.S. Food and Drug Administration; 2014 Jun 17. URL: http://blogs. fda.gov/fdavoice/index.php/2014/06/

fda-issues-draft-guidances-for-industry-on-social-media-and-internet-communications-about-medical-products-designed-with-patients-in-mind/ ?source=govdelivery\&utm_medium=email\&utm_source=govdelivery [accessed 2017-06-16] [WebCite Cache ID 6m2tWDFqA]

9. U.S. Department of Health and Human Services, Food and Drug Administration, Center for Drug Evaluation and Research, Center for Biologics Evaluation and Research, Center for Veterinary Medicine, Center for Devices and Radiological Health. Guidance for industry: internet/social media platforms with character space limitations--presenting risk and benefit information for prescription drugs and medical devices. Draft guidance. Silver Spring, MD: U.S. Food and Drug Administration; 2014 Jun. URL: http://www.fda.gov/downloads/Drugs/GuidanceComplianceRegulatoryInformation/Guidances/UCM401087. pdf [accessed 2017-06-16] [WebCite Cache ID 6m2toySXa]

10. Abel GA, Lee SJ, Weeks JC. Direct-to-consumer advertising in oncology: a content analysis of print media. J Clin Oncol 2007 Apr 01;25(10):1267-1271. [doi: 10.1200/JCO.2006.09.5968] [Medline: 17401016]

11. Avery RJ, Eisenberg M, Simon KI. Fair balance in direct-to-consumer antidepressant print and television advertising, 1995-2007. J Health Commun 2012;17(3):250-277. [doi: 10.1080/10810730.2011.585698] [Medline: 22107455]

12. Kaphingst KA, Rudd RE, DeJong W, Daltroy LH. Literacy demands of product information intended to supplement television direct-to-consumer prescription drug advertisements. Patient Educ Couns 2004 Nov;55(2):293-300. [doi: 10.1016/j.pec.2003.11.003] [Medline: 15530767]

13. Frosch DL, Krueger PM, Hornik RC, Cronholm PF, Barg FK. Creating demand for prescription drugs: a content analysis of television direct-to-consumer advertising. Ann Fam Med 2007;5(1):6-13 [FREE Full text] [doi: 10.1370/afm.611] [Medline: 17261859]

14. Kaphingst KA, DeJong W, Rudd RE, Daltroy LH. A content analysis of direct-to-consumer television prescription drug advertisements. J Health Commun 2004;9(6):515-528. [doi: 10.1080/10810730490882586] [Medline: 15764450]

15. Macias W, Pashupati K, Lewis LS. A wonderful life or diarrhea and dry mouth? Policy issues of direct-to-consumer drug advertising on television. Health Commun 2007;22(3):241-252. [doi: 10.1080/10410230701626893] [Medline: 17967146]

16. Hicks KE, Wogalter MS, Vigilante WJ. Placement of benefits and risks in prescription drug manufacturers' websites and information source expectations. Ther Innovation Regul Sci 2005 Jul 01;39(3):267-278. [doi: 10.1177/009286150503900305]

17. Huh J, Cude BJ. Is the information "fair and balanced" in direct-to-consumer prescription drug websites? J Health Commun 2004;9(6):529-540. [doi: 10.1080/10810730490882667] [Medline: 15764451]

18. Sheehan KB. Direct-to-consumer (DTC) branded drug web sites: risk presentation and implications for public policy. J Advertising 2007 Oct;36(3):123-135. [doi: 10.2753/JOA0091-3367360310]

19. Tyrawski J, DeAndrea DC. Pharmaceutical companies and their drugs on social media: a content analysis of drug information on popular social media sites. J Med Internet Res 2015;17(6):e130 [FREE Full text] [doi: 10.2196/jmir.4357] [Medline: 26032738]

20. Adams C. Fair balance and adequate provision in direct-to-consumer prescription drug online banner advertisements: a content analysis. J Med Internet Res 2016 Feb 18;18(2):e33 [FREE Full text] [doi: 10.2196/jmir.5182] [Medline: 26892749]

21. U.S. Food and Drug Administration. Drugs@FDA: FDA approved drug products. Silver Spring, MD: U.S. Department of Health and Human Services URL: http://www.accessdata.fda.gov/scripts/cder/drugsatfda/ [accessed 2017-06-14] [WebCite Cache ID 6rDiCi92U]

22. U.S. Food and Drug Administration, Department of Health and Human Services. Requirements on content and format of labeling for human prescription drug and biological products: final rule. Federal Register 2006 Jan 24;71(15):3922-3997 [FREE Full text]

23. Gilbody S, Wilson P, Watt I. Benefits and harms of direct to consumer advertising: a systematic review. Qual Saf Health Care 2005 Aug;14(4):246-250 [FREE Full text] [doi: 10.1136/qshc.2004.012781] [Medline: 16076787]

24. Mintzes B. Advertising of prescription-only medicines to the public: does evidence of benefit counterbalance harm? Annu Rev Public Health 2012 Apr;33:259-277. [doi: 10.1146/annurev-publhealth-031811-124540] [Medline: 22429162]

25. Niederdeppe J, Byrne S, Avery RJ, Cantor J. Direct-to-consumer television advertising exposure, diagnosis with high cholesterol, and statin use. J Gen Intern Med 2013 Jul;28(7):886-893 [FREE Full text] [doi: 10.1007/s11606-013-2379-3] [Medline: 23463454]

26. Millennial Media. Some S.M.A.R.T. summer reading. 2014 Jun 27. URL: http://www.millennialmedia.com/mobile-insights/ blog/some-smart-summer-reading [accessed 2017-03-13] [WebCite Cache ID 6ow80PTFY] 
27. Pharmaceutical Research and Manufacturers of America. PhRMA Guiding principles for direct to consumer ads on medicines. 2013 Apr 8. URL: http://www.phrma.org/codes-and-guidelines/

phrma-guiding-principles-for-direct-to-consumer-ads-on-medicines [accessed 2017-03-13] [WebCite Cache ID 6ow8KhnE8]

28. U.S. Food and Drug Aministration. 2009 warning and untitled letters to pharmaceutical companies. 2009. URL: http:/ /wayback.archive-it.org/7993/20170111082216/http://www.fda.gov/Drugs/GuidanceComplianceRegulatoryInformation/ EnforcementActivitiesbyFDA/WarningLettersandNoticeofViolationLetterstoPharmaceuticalCompanies/ucm055773.htm [accessed 2017-06-19] [WebCite Cache ID 6rLPFHU18]

29. Grant L. regulations.gov. 2017 Jan 05. RE: Docket No. FDA-2016-N-3585 Character-space-limited online prescription drug communications URL: https://www.regulations.gov/document?D=FDA-2016-N-3585-0006 [accessed 2017-06-19] [WebCite Cache ID 6rLPUZktf]

30. Sullivan HW, O'Donoghue AC, Rupert DJ, Willoughby JF, Aikin KJ. Placement and format of risk information on direct-to-consumer prescription drug websites. J Health Commun 2017 Feb;22(2):171-181. [doi:

10.1080/10810730.2016.1258745] [Medline: 28129069]

31. Abrams TW. Novartis oncology 4/21/10 warning letter. Silver Spring, MD: U.S. Food and Drug Administration; 2010 Apr 21. URL: http://wayback.archive-it.org/7993/20170112062836/http://www.fda.gov/Drugs/

GuidanceComplianceRegulatoryInformation/EnforcementActivitiesbyFDA/

WarningLettersandNoticeofViolationLetterstoPharmaceuticalCompanies/ucm259229.htm [accessed 2017-06-19] [WebCite Cache ID 6rLPj83T7]

32. Aikin KJ, Sullivan HW, Betts KR. Disease information in direct-to-consumer prescription drug print ads. J Health Commun 2016;21(2):228-239. [doi: 10.1080/10810730.2015.1058440] [Medline: 26717304]

33. Sullivan HW, O'Donoghue AC, Rupert DJ, Willoughby JF, Amoozegar JB, Aikin KJ. Are disease awareness links on prescription drug websites misleading? A randomized study. J Health Commun 2016 Nov;21(11):1198-1207. [doi: 10.1080/10810730.2016.1237594] [Medline: 27805473]

34. Reeves K, Russell G. Law360. 2015 year in review: drug promotion warning letters. New York, NY: Portfolio Media Inc; 2016 Mar 17. URL: http://www.kslaw.com/imageserver/KSPublic/library/publication/2016articles/3-17-2016_Law360.pdf [accessed 2017-06-16] [WebCite Cache ID 6rGRCSQjb]

\section{Abbreviations \\ CDER: Center for Drug Evaluation and Research \\ DTC: direct-to-consumer \\ FDA: US Food and Drug Administration}

Edited by L Buis; submitted 18.01.17; peer-reviewed by D DeAndrea, C Adams, BL Rollins, E Doran; comments to author 16.02.17;
revised version received 03.04.17; accepted 05.06.17; published 04.07.17
Please cite as:
Aikin KJ, Sullivan HW, Dolina S, Lynch M, Squiers LB
Direct-to-Consumer Promotion of Prescription Drugs on Mobile Devices: Content Analysis
J Med Internet Res 2017;19(7):e225
URL: $\underline{\text { http://www.jmir.org/2017/7/e225/ }}$
doi: $\underline{10.2196 / j m i r .7306}$
PMID: $\underline{28676469}$

CKathryn J Aikin, Helen W Sullivan, Suzanne Dolina, Molly Lynch, Linda B Squiers. Originally published in the Journal of Medical Internet Research (http://www.jmir.org), 04.07.2017. This is an open-access article distributed under the terms of the Creative Commons Attribution License (https://creativecommons.org/licenses/by/4.0/), which permits unrestricted use, distribution, and reproduction in any medium, provided the original work, first published in the Journal of Medical Internet Research, is properly cited. The complete bibliographic information, a link to the original publication on http://www.jmir.org/, as well as this copyright and license information must be included. 